others decorated for bravery in the field-the Société d'Anthropologie still continues its meetings. I was able to inform Prof. Manouvrier that the sister society in London, in common with other English scientific societies, also continued its meetings, that many of its members-including the honorary secretary and assistant-secretary, had volunteered for active service, and that a member of the council (Major S. L. Cummins) had been decorated with the Legion of Honour.

"Pour moi," writes Prof. Manouvrier, in concluding his letter, "je ne puis plus qu'un vétéran-un ancien volontaire de 1870 . Je fus ainsi un très obscur compagnon d'armes de notre aimé Lord Kitchener."

Royal College of Surgeons, Lincoln's Inn Fields, W.C.

\section{A Central Thought of Vector Analysis as used in Physics.}

VECTOR analysis is now recognised fully as furnishing standard modes of expression for many ranges of mathematical and physical thought; and meanwhile, the atmosphere of the physical thought especially is continually reacting upon the newer analytic method, and adapting it with preciser discrimination to the needs of actual use. Thus the dichotomous arrangement of quantities as scalar or vector has been supplemented by the tensor-triplet as a tertium quid, vectors are habitually grouped as free or localised, pseudo-scalars have been set off from pure scalars. Something has been done, too, through the influence of ascertained physical connections, toward unifying discrete formal results by appreciating real underlying articulation. Such advances as are made deserve immediate incorporation in the accepted text, as likely to render the methods more widely available; and the serving of that end has suggested presenting the notes that follow.

Most of the orthodox lines of development leave scalar product and vector product isolated from one another, each sharply differentiated by its own special definition. And an impression is then ordinarily felt that the novel characteristics of vector analysis in cutting through the rules of algebra centre upon the vector product. What there may be of exaggeration in this impression can be corrected by very simple and accessible considerations. First we may observe that an axial vector and a vector product are essentially two aspects of the same conception, the former being potentially resolvable into two factors determining an oriented area that is at the same time the geometrical basis of the vector product. But the projection of areas and their graphic representation by their measured normals are familiar elementary notions; while the assignment of "circulation" round the perimeter to an area, being necessary in order to complete the plan of conventional representation, must be expected to appear also in the equivalent vector product. In fact, the rule for sequence of the factors there and the change of sign upon reversal of that sequence are only assignment of circulation scarcely disguised. To establish the connection is to restore the emphasis of Grassmaun's thought where it may have been neglected.

At another point current procedure is apt to dislocate the vector product from its natural or original setting, and encourage a misleading effect of antithesis where there is in reality more nearly a complementary relation. When a scalar product and its corresponding vector product are introduced separately and held apart by exclusive stress upon their divergence of type, an instructive link uniting them is lost sight of or ignored. At their source they are linked in that completer combination of two vectors according to the fundamental idea of multiplication of which they are partial aspects. Again it is GrassNO. 2354 , VOL. 94] maun who more than hints at this very point of view presented also in a somewhat different dress by the quaternion and the dyad. For purposes of elementary introduction the relation in question comes, perhaps, most clearly into prominence if the vector factors to be combined are from the outset of this particular development written each as - a "semi-cartesian" trinomial, yielding thus nine terms for the presentation of the completed combination. On inspection three of these terms are obviously scalar; they. constitute the "scalar product" (or expressed more fully the "scalar side of the product"). The remaining six terms are just as obviously to be accepted as vectors in their nature; together they constitute the "vector product" (or the complementary "vector side of the product"). These mutual complements make up the complete expression into which they enter, though they cannot coalesce, very much as a complex quantity contains a real term and a detachable imaginary term.

The value of the more inclusive statement is to be rated still higher in its justifiable extension to the combination of Hamilton's operator with a fieldvector, which is also expressible formally as the expanded product of two trinomials, the nine terms of which, here too distinguishable as scalar and vector to unstrained interpretation, are presently grouped under the headings "divergence" and "curl." For the complete combination that might be written $(\nabla \mathrm{V})$ is intended to place in our hands by its results a means of specifying with all reasonably attainable detail the local peculiarities of distribution for the field-vector. And here the usual partition of the specification into apparently quite disconnected divergence and curl seems plainly artificial at first sight, and becomes yet more so as we trace out the intimately complementary character of the two items in the description. It will always be helpful to emancipate ourselves from the formal constraints of our algebra, which here, for example, in a degree forbid the association of scalar and vector parts, and aim on the contrary, through the choice of orthogonal components, at a segregation at once complete and reduced to simplest terms. We remember with profit that one main office of the vector analysis is to do away with those mechanical features of algebra which contribute nothing or little to the progress of thought.

University of California.

\section{Science and National Needs.}

IN a recent issue of NATURE (October 29, p. 222) the remark occurs :-

"In this hour of national emergency there is no time to be lost. We cannot all be soldiers, but we can all help, we men of science, in securing victory for the allied armies. Every day lost means the destruction of a number of our fellow-countrymen and of our allies, and the sooner we co-operate for the good of the nation the sooner will the war be over."

Acting upon the suggestion, and bearing in mind the manner in which the dew-ponds on Salisbury Plain suffered during the drought of IgII, I immediately offered my services to the War Office, to advise as to the digging of dew-ponds and the choice of sites for them.

I find that there is not now so great a necessity for them there as formerly, as water has been laid on to many of the camps, but should the necessity arise anywhere that camps are placed, the War Office has my offer before them.

I write this in order to encourage others to do what in them lies. EDWARD A. MarTiN.

285 Holmesdale Road, South Norwood, S.E. 